\title{
nature
}

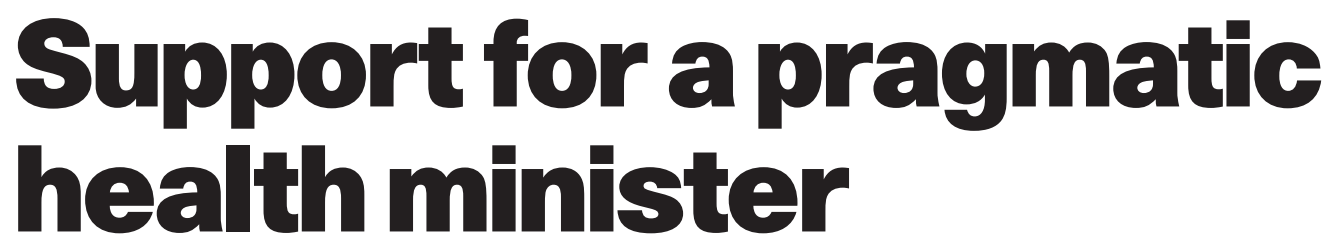

Cancer patients in Italy are threatening their own survival through faith in a miracle cure. But the government is justified in sanctioning controlled tests of the therapy, even if it lacks a scientific basis.

A stonishingly and scandalously, a frail 85-year-old physician, Luigi Di Bella, has managed to precipitate a crisis in relations between the public, science and government in Italy with his brand of cancer therapy, a cocktail of vitamins and minerals that also includes the drug somatostatin. Dismissed as ineffective by the scientific establishment, the therapy has nevertheless been hailed as a miracle cure by the public.

Early experience with somatostatin in the 1980s and early 1990s indicated that its theoretical promise as an anticancer agent was limited to some rare neuroendocrine tumours. Nonetheless, Di Bella, postulating that somatostatin stimulates the body to rid itself of any type of cancer, has claimed to have cured thousands of patients (see Nature 391, 217; 1998). But he has no documentation or publications to back his claims. The health minister Rosy Bindi was therefore right earlier last year to ignore requests from so-called Di Bellists to conduct clinical trials for somatostatin in cancer and to place it on the national list of reimbursable drugs.

But the situation has changed dramatically: this is no longer simply a scientific issue but has become polarized and politicized. Demonstrations of tens of thousands have become a regular event, football supporters wave banners demanding freedom of treatment, and reports of cancer sufferers dying because they were denied the Di Bella treatment dominate newspaper headlines and television debates.

The right-wing opposition party Alleanza Nazionale has formally adopted a policy supporting Di Bella — to be against him is now seen to be left wing - and, more worryingly, the judiciary has backed Di Bella's case against the government, citing an article in the constitution that guarantees to protect the health of individuals. Local courts have ordered individual patients to be treated with somatostatin without charge, and a national court last month, defying Bindi, ordered the head of the government's pharmaceutical committee to put somatostatin on the national reimbursable drugs list - an order that has since been overturned by a higher court. Italy's constitutional court is now considering the rights of the judiciary to overrule the government on health issues.

In view of this turmoil, Bindi was right when she decided in January to reverse her decision and order clinical trials to be carried out as soon as possible, despite a lack of scientific basis for the therapy. Ten multicentre phase II trials, designed by the country's leading oncologists, began last week, at an estimated cost of IL20 billion (US\$11 million).

The drama of the Di Bella phenomenon may be perceived as peculiarly Italian, but at its core there are parallels with the history of patient power elsewhere. In the United States, patients dying of AIDS successfully persuaded the Food and Drug Administration (FDA) to deviate from its traditional slow drug licensing procedures and make AZT available before clinical trials were completed.

And in the 1980s the FDA was forced to conduct clinical trails on laetrile, a cyanide containing extract of apricot stones of even less therapeutic value than somatostatin. In both cases, concessions by government proved productive in calming the situation; laetrile is a fad of the past, whereas AZT has found its natural level in AIDS therapy.

Some Italian scientists, at least, deplore the sidelining of science as the government, as they see it, bows to emotional pressure in the Di Bella case. They are right to state the scientific case but wrong to oppose Bindi's pragmatic solution. To ignore the emotional element in the public response is to omit a critical factor from the problem and thereby render it insoluble.

\section{Diplomats need science}

\section{A lack of scientific and technical expertise among diplomats is likely to marginalize the diplomatic corps.}

$\mathrm{n}$ response to recurrent concerns that the US State Department is unable or unwilling to integrate science into US foreign policy, the National Academy of Sciences has been invited to conduct a fresh review of the status of science in the department (see page 427). No doubt the academy will find sizeable flaws in its handling of scientific issues, reflecting the view of science policy experts expressed in testimony before the House of Representatives Science Committee last week as on previous occasions - that the State Department neglects science. Reforming this situation in an institution that is so large and entrenched is clearly more easily said than done.

Before spending much energy on the attempt, the community should ask itself to what extent the State Department's alleged neglect really matters to research. In one or two respects it does.
Neglect of science and technology at the diplomatic level makes it harder to forge international agreement on scientific collaboration. This weakness has inflicted some damage on various large scientific projects, such as the abandoned Superconducting Super Collider. For the wider global scientific enterprise, the State Department and its equivalents in other countries matter less and less. In science as in commerce, except where intergovernmental agreements are concerned, the process of globalization will increasingly allow international communication to bypass official channels altogether.

But, no less than in the Cold War era, science and technology collaboration can help to build or reinforce good relations between countries. In short, the State Department needs science rather more than science needs the State Department. 